\title{
Peptidase Modulation of Vasoactive Intestinal Peptide Pulmonary Relaxation in Tracheal Superfused Guinea Pig Lungs
}

\author{
Craig M. Lilly, Milton A. Martins," and Jeffrey M. Drazen** \\ *Combined Program in Pulmonary and Critical Care Medicine, Departments of Medicine, Beth Israel Hospital and Brigham and \\ Women's Hospital, and Harvard Medical School; Ina Sue Perlmutter Laboratory, Children's Hospital; and \\ ${ }^{\ddagger}$ Respiratory Biology Program, Harvard School of Public Health, Boston, Massachusetts 02215
}

\section{Abstract}

The effects of enzyme inhibitors on vasoactive intestinal peptide (VIP)-induced decreases in airway opening pressure (Pao) and VIP-like immunoreactivity (VIP-LI) recovery were studied in isolated tracheal superfused guinea pig lungs. In the absence of inhibitors, VIP 0.38 (95\% CI 0.33-0.54) nmol/kg animal, resulted in a 50\% decrease in Pao and 33\% of a 1 nmol/kg VIP dose was recovered as intact VIP. In the presence of two combinations of enzyme inhibitors, SCH 32615 (S, $10 \mu \mathrm{M})$ and aprotinin (A, 500 tyrpsin inhibitor units [TIU]/kg) or $S$ and soybean trypsin inhibitor (T, 500 TIU/kg), VIP caused a significantly greater decrease in Pao and greater quantities of VIP were recovered from lung effluent (both $P<0.001$ ). The addition of captopril, (3 $\mu \mathrm{M})$, leupeptin $(4 \mu \mathrm{M})$, or bestatin $(1 \mu \mathrm{M})$ failed to further increase pulmonary relaxation or recovery of VIPLI. When given singly, A, T, and $S$ did not augment the effects or recovery of VIP. The efficacy of S (a specific inhibitor of neutral endopeptidase [NEP]) and $A$ and $T$ (serine protease inhibitors) thus implicated NEP and at least one serine protease as primary modulators of VIP activity in the guinea pig lung. We sought to corroborate this finding by characterizing the predominant amino acid sites at which VIP is hydrolized in the lung. When [mono( ${ }^{125}$ I)iodo-Tyr ${ }^{10}$ ]VIP was offered to the lung, in the presence and absence of the active inhibitors, cleavage products consistent with activity by NEP and a tryptic enzyme were recovered. These data demonstrate that NEP and a peptidase with an inhibitor profile and cleavage pattern compatible with a tryptic enzyme inactivate VIP in a physiologically competitive manner. (J. Clin. Invest. 1993. 91:235-243.) Key words: vasoactive intestinal peptide • SCH 32615 - aprotinin • soybean trypsin inhibitor - captopril • bestatin - leupeptin • neutral endopeptidase (NEP) • tryptase

Address correspondence to Jeffrey M. Drazen, Combined Program in Pulmonary and Critical Care Medicine, Brigham and Women's Hospital, 75 Francis Street, Boston, MA 02115. 1992.

Received for publication 15 April 1992 and in revised form 29 July

1. Abbreviations used in this paper: A, aprotinin; B, bestatin; C, captopril; $\mathrm{CI}$, confidence interval; $\mathrm{IC}_{\mathbf{5 0}}$, inhibitor concentration resulting in $50 \%$ inhibition; L, leupeptin; NEP, neutral endopeptidase; Pao, back pressure resulting from tracheal perfusion; RP-HPLC, reverse-phase HPLC; S, enzyme inhibitor SCH 32615; T, soybean trypsin inhibitor; TFA, trifluoroacetic acid; VIP, vasoactive intestinal peptide; VIP-LI, VIP-like immunoreactivity.

J. Clin. Invest.

(c) The American Society for Clinical Investigation, Inc.

0021-9738/93/01/0235/09\$2.00

Volume 91, January 1993, 235-243

\section{Introduction}

Vasoactive intestinal peptide (VIP) ${ }^{1}$ is a 28 -residue amidated carboxyl-terminal peptide with pulmonary relaxant activity (1-3). In the lung, VIP is found in neurons located at the medial-adventitial junction of pulmonary and bronchial vessels $(4,5)$. VIP is also present in cells subtending the smooth muscle layer and in glands of airways, including small bronchi (6). Although VIP has been shown to relax constricted airways and to inhibit glandular secretion $(2,7-10)$, its potency appears to be limited by enzymatic degradation in the pulmonary microenvironment. In isolated guinea pig (2) and human pulmonary contractile tissues, enzyme inhibitors have been shown to enhance VIP-induced relaxation $(3,11,12)$, but the enzyme systems responsible for limiting VIP-induced pulmonary relaxation have not been identified. Neutral endopeptidase (EC 3.4.24.11 [NEP]) and mast cell proteases have been shown, in isolated systems, to cleave VIP with kinetics consistent with activity under physiological conditions $(3,12-17)$. Since endogenously released VIP may become available on the airway epithelium, we used the tracheal superfused lung $(18,19)$ to examine the physiologically relevant pathways responsible for the enzymatic inactivation of VIP. Our data suggest that the pulmonary relaxant activity of VIP is limited by enzymatic cleavage by NEP and a second protease with a cleavage pattern and inhibitor profile consistent with a tryptic enzyme.

\section{Methods}

Tracheal superfusion. Tracheal superfusion was performed as previously described (19). 123 male Hartley-strain guinea pigs, 330-410 g body wt, were anesthetized with $65 \mathrm{mg} / \mathrm{kg}$ sodium pentobarbital given by intraperitoneal injection. When an appropriate plane of anesthesia was achieved, a tracheostomy was created and a 2-cm length of polyethylene tubing ( $1.67 \mathrm{~mm}$ i.d., $2.42 \mathrm{~mm}$ o.d.) was placed in the trachea. The abdominal cavity was opened and $500 \mathrm{U}$ of heparin were injected into the vena cava. 3 min later the abdominal aorta was severed and the guinea pig was exsanguinated. The thoracic cavity was widely opened and the heart and lungs were removed en bloc. The lungs were dissected free and placed in a $37^{\circ} \mathrm{C}, 100 \%$ relative humidity plexiglass box. The lungs were superfused with a phosphate-buffered physiological solution with the following composition (mM): $137 \mathrm{NaCl}, 1.8 \mathrm{CaCl}_{2}$, $1.05 \mathrm{MgCl}_{2}, 2.68 \mathrm{KCl}, 0.6 \mathrm{NaHCO}_{3}, 0.13 \mathrm{NaH}_{2} \mathrm{PO}_{4}, 0.896 \mathrm{Na}_{2} \mathrm{HPO}_{4}$, pH 7.4. The perfusion buffer was warmed to $45^{\circ} \mathrm{C}$ and pumped at 5 $\mathrm{ml} / \mathrm{min}$ through a bubble trap before being cooled to $37^{\circ} \mathrm{C}$ and entered into the lungs through the tracheal cannula. Perfusate exited the lungs via numerous small holes placed in the pleura and was collected on ice in polypropylene tubes containing glacial acetic acid (5\% by final volume) and was analyzed as indicated below. The "back pressure" resulting from tracheal perfusion (Pao) was recorded from a side tap at the tracheal cannula using a pressure transducer (P23Db; Statham Instruments Inc., Oxnard, CA). We have previously shown that, at continuous flow, Pao reflects the contractile state of the lung (19). All experiments involving animals or tissues were approved by the animal care and use committees of both the Beth Israel and Children's Hospitals.

Determination of the time course and dose response of VIP-induced 
pulmonary relaxation. At the start of superfusion Pao rose slowly and reached a stable plateau after $15 \mathrm{~min}$. Preliminary studies indicated that when airway tone was increased, by adding $10^{-7} \mathrm{M}$ methacholine to the perfusion buffer, VIP caused rapid decreases in Pao, hence all data are reported in lungs with methacholine-induced airway tone. To establish the time course of VIP-induced relaxation, two groups of five lungs were tracheally injected with either $1 \mathrm{nmol} / \mathrm{kg}$ VIP (all doses were given per kilogram animal) (diluted in $100 \mu \mathrm{l}$ perfusion buffer) or 100 $\mu \mathrm{l}$ of buffer alone, while Pao was recorded over a 15-min observation period. To establish a dose-response relationship for $\mathrm{Pao}$ as a function of VIP dose, five lungs were tracheally injected with geometrically increasing doses of VIP, from $10 \mathrm{pmol}$ to $100 \mathrm{nmol}$, given at 5-min intervals. For each lung, maximal relaxation was determined by tracheally injecting $10 \mathrm{nmol} / \mathrm{kg}$ of isoproterenol; a dose of isoproterenol shown in preliminary studies to elicit a maximal fall in Pao.

Perfusion with protease inhibitors. Ten groups of five animals each were superfused as described above; when a stable Pao had been achieved $1 \mathrm{nmol} / \mathrm{kg}$ VIP or an equivalent volume of buffer was tracheally injected. VIP was administered with or without enzyme inhibitors, alone or in combination, added to the tracheal perfusate in the following concentrations: captopril (C), $3 \mu \mathrm{M}$; aprotinin (A), 500 trypsin inhibitor units (TIU) (1 TIU will decrease the activity of two trypsin units by $50 \%$ where one trypsin unit will hydrolyze $1 \mu \mathrm{mol}$ of $N \alpha$-benzoyl-DL-arginine $p$-nitroanilide/min at $\mathrm{pH}=7.8$ and $25^{\circ} \mathrm{C}$ ) per kilogram animal; bestatin (B), $1 \mu \mathrm{M}$; leupeptin (L), $4 \mu \mathrm{M}$; SCH 32615 (S), $10 \mu \mathrm{M}$; and soybean trypsin inhibitor (T), $500 \mathrm{TIU} / \mathrm{kg}$ animal. Groups of five animals each were superfused under the following conditions: no inhibitors and no VIP injection (NO VIP); no inhibitors and a VIP injection (VIP); single inhibitors and a VIP injection: S, A, T; and combinations of inhibitors and a VIP injection: CBLS, CABLS, CTBLS, AS, and TS.

Recovery of VIP-like immunoreactivity. Lung effluent, from the same lungs described above in the "Perfusion with enzyme inhibitors" section was assayed for VIP-like immunoreactivity. After administration of $1 \mathrm{nmol} / \mathrm{kg}$ VIP, a 5-min fraction of lung effluent was collected on ice in a polypropylene tube containing $5 \%$ by final volume glacial acetic acid. This fluid was processed as described below.

VIP immunoassay sample preparation. Lung effluent containing $5 \%$ acetic acid was applied to a Sep-Pak ${ }^{\circledast} \mathrm{C}_{18}$ cartridge (Millipore Corp., Bedford, MA) which was prewashed with $20 \mathrm{ml}$ methanol followed by $20 \mathrm{ml}$ distilled $\mathrm{H}_{2} \mathrm{O}$. In the time course experiment the cartridges were eluted with $3 \mathrm{ml}$ of $60 \%$ acetonitrile and $40 \% \mathrm{H}_{2} \mathrm{O}$ with $0.1 \%$ trifluoroacetic acid (TFA) titrated to $\mathrm{pH} 2.5$ with triethylamine; in the inhibitor study the cartridges were eluted with $100 \%$ methanol. The cartridge eluate was dried under vacuum (Savant Instruments Inc., Farmingdale, NY) and stored at $-20^{\circ} \mathrm{C}$ until resuspended in $100 \mu \mathrm{l}$ of a $50 \%$ methanol, $50 \% 0.1 \mathrm{~N} \mathrm{HCl}$ solution for immunoassay.

Immunoassay of VIP. VIP was measured in lung effluent by solidphase ELISA, modified from the method described by Folkesson et al. (20) for substance P. VIP ELISA plates were made by incubating VIP (5 ng per well) conjugated to bovine serum albumin (The VIP-BSA conjugate was made by adding $2.1 \mathrm{mg}$ guinea pig VIP, 20,000 dpm ${ }^{125} \mathrm{I}-\mathrm{VIP}$, and $10.5 \mathrm{mg}$ BSA to $735 \mu \mathrm{l}$ of PBS solution, $\mathrm{pH}=7.4$, on ice. $360 \mu \mathrm{l}$ of $25 \%$ glutaraldehyde in HPLC grade $\mathrm{H}_{2} \mathrm{O}$ was added slowly and the resulting solution was incubated for $30 \mathrm{~min}$ at $0^{\circ} \mathrm{C}$ for $2 \mathrm{~h}$ at room temperature and was then extensively dialyzed against $0.01 \mathrm{M}$ PBS.) in flat-bottomed polyvinyl microtiter plates. After incubation for $4 \mathrm{~h}$ at room temperature, the plate was washed once in $0.15 \mathrm{M} \mathrm{NaCl}$ containing $0.05 \%$ Tween 20 , blocked with $3 \%$ normal goat serum $(200 \mu$ per well), and incubated at room temperature for $1 \mathrm{~h}$. The plate was washed three times with $0.15 \mathrm{M} \mathrm{NaCl}$ containing $0.05 \%$ Tween 20 and once with distilled water. After drying the plates were wrapped in Parafilm ${ }^{\otimes}$ (American National Can Co., Greenwich, CT) and stored at $-20^{\circ} \mathrm{C}$ until use. At the time of assay, samples and VIP standards $\left(3 \times 10^{-7}\right.$ $10^{-11} \mathrm{M}$ ) were dissolved in a solution of $50 \%$ methanol, $50 \% 0.1 \mathrm{~N} \mathrm{HCl}$; $25 \mu \mathrm{l}$ of each solution was added to a tube containing $200 \mu \mathrm{l}$ of the primary antibody solution. The primary antibody solution contained
$175 \mu \mathrm{l}$ anti-VIP antiserum (RAS $7161 \mathrm{~N}$; Peninsula Laboratories Inc., Belmont, CA), $600 \mu \mathrm{l}$ normal goat serum, $4 \mathrm{ml} 0.5 \mathrm{M}$ PBS containing $0.25 \%$ Tween $20, \mathrm{pH}=7.4$, and $15.4 \mathrm{ml}$ distilled $\mathrm{H}_{2} \mathrm{O}$. After $1 \mathrm{~h}, 100 \mu \mathrm{l}$ of each solution was transferred to a VIP ELISA plate well and incubated at $4^{\circ} \mathrm{C}$ for $72 \mathrm{~h}$. The plates were then washed three times in 0.15 $\mathrm{M} \mathrm{NaCl}$ containing $0.05 \%$ Tween 20 and incubated for $2 \mathrm{~h}$ at $37^{\circ} \mathrm{C}$ with horseradish peroxidase-linked anti-rabbit antibody (NA934; Amersham International, Amersham, UK). The plates were washed three times in $0.15 \mathrm{M} \mathrm{NaCl}$ with $0.05 \%$ Tween 20 , developed with p-phenylenediamine substrate for $30 \mathrm{~min}$, and the reaction was stopped by adding $100 \mu \mathrm{l} 2.5 \mathrm{M} \mathrm{H}_{2} \mathrm{SO}_{4}$. The absorbance of each well was measured at $492 \mathrm{~nm}$ (Dynatech Laboratories, Inc., Chantilly, VA). The assay's lower limit of detection was $3 \mathrm{fmol}$ of VIP; we found $<0.1 \%$ cross-reactivity to VIP $1-22$, VIP 5-22, VIP $1-14$, VIP $5-14$, and VIP 13-28. VIP 5-28 had < 5\% cross-reactivity with VIP 1-28.

Time courses of VIP recovery. To determine the time course of recovery of injected VIP and VIP cleavage products in lung effluent, three lungs were superfused and tracheally injected with $125,000 \mathrm{dpm}$ of ${ }^{125}$ I-VIP while 1-min fractions were collected; recovery of radiolabel was assessed by gamma counting these fractions. To determine the recovery of intact VIP, three lungs were superfused and tracheally injected with $1 \mathrm{nmol} / \mathrm{kg}$ VIP while 1 -min fractions of lung effluent were collected for immunoassay. To determine the physiological activity of VIP fragments, groups of three animals were superfused and tracheally injected with geometrically increasing doses, from $100 \mathrm{pmol} / \mathrm{kg}$ to 1 $\mu \mathrm{mol} / \mathrm{kg}$, of VIP fragments and Pao was measured.

Recovery of ${ }^{125}$ I-VIP hydrolysis fragments from lung effluent. Radiolabeled VIP was perfused through the lung, effluent was collected, and radiolabeled fragments were resolved by reverse-phase HPLC (RPHPLC). Retention times were compared with those of radiolabeled peptide standards with sequences that would result from hydrolysis of VIP at sites preferred by recombinant or highly purified NEP, chymase, and tryptase. Lungs were superfused as described above and after Pao had stabilized, a 5-min pre-injection control sample of lung effluent was collected on ice in 5\% glacial acetic acid. A second 5-min fraction of lung effluent was collected after tracheal injection of $250,000 \mathrm{dpm}$ of $\left[\right.$ mono $\left.{ }^{125} \mathrm{I}\right)$ iodo-Tyr ${ }^{10}$ ]VIP. Samples were dried under vacuum, resuspended in $600 \mu$ l of HPLC grade $\mathrm{H}_{2} \mathrm{O}$ with $0.1 \%$ (vol/vol) TFA, divided into two $300-\mu \mathrm{l}$ aliquots, passed through a $0.22-\mu \mathrm{m}$ filter (Millipore Corp., Bedford, MA), and subjected to RP-HPLC analysis. Lung effluent was analyzed from four groups of two lungs superfused with buffer containing the following inhibitor combinations (at concentrations defined above) added to the superfusate: CBL, CABL, CBLS, and CABLS

Preparation of $\left[\right.$ mono $\left({ }^{125}\right.$ I)iodo-Tyr $\left.{ }^{10}\right]$ VIP and $\left[\left({ }^{125} I\right)\right.$ iodo-Tyr $\left.{ }^{10}\right]-$ VIP fragments. VIP or VIP fragments were iodinated by the method of Martin et al. (21). $1.5 \mathrm{nmol}$ of VIP or a VIP fragment was dissolved in $25 \mu \mathrm{l}$ of $0.3 \mathrm{M} \mathrm{PBS}, \mathrm{pH}=7-11$, and $1 \mathrm{mCi}$ of carrier-free sodium iodide ( $0.5 \mathrm{nmol}$ in $10 \mu \mathrm{l} \mathrm{NaOH}, \mathrm{pH}=7.4$; Amersham International), was added, providing $\approx 3$ molecules of VIP or VIP fragment for each ${ }^{125}$ I atom. While stirring, iodination was initiated with the addition of 14.2 nmol of chloramine-T at a concentration of $1 \mathrm{mg} / \mathrm{ml}$. After $15 \mathrm{~s}$ at room temperature the reaction was terminated by adding $42.1 \mathrm{nmol}$ of $\mathrm{Na}_{2} \mathrm{~S}_{2} \mathrm{SO}_{5}$. The reaction mixture was applied to a Sep-Pak ${ }^{\otimes} \mathrm{C}_{18}$ cartridge and washed with $9 \mathrm{ml}$ of HPLC grade $\mathrm{H}_{2} \mathrm{O}$ with $0.1 \%$ TFA. ${ }^{125} \mathrm{I}$-VIP or ${ }^{125} \mathrm{I}$-VIP fragments were eluted in a solution of $60 \%$ acetonitrile and $40 \% \mathrm{H}_{2} \mathrm{O}$ with $0.1 \%$ TFA ( $\mathrm{pH} 2.5$ ). The eluate was purified by $\mathrm{C}_{18}$ reverse-phase chromatography using the RP-HPLC protocol described below as protocol I. Two sequential HPLC purification steps yielded a material with a single peak and a reproducible retention time. Purified material was stored at $4^{\circ} \mathrm{C}$ and was used the next day.

Identification of VIP and VIP hydrolysis fragments in lung effluent. Identification of potential VIP cleavage products that would be formed by action of NEP, chymase, or tryptase, $(13,14)$, i.e., VIP $1-22$, VIP 1-21, VIP 1-14, VIP 4-14, VIP 5-14, VIP 5-21, VIP 5-22, VIP 5-28, VIP 9-10, VIP 10-11, VIP 21-22, VIP 22-23, and VIP 22-28, was accomplished by comparing the RP-HPLC retention time of authentic ${ }^{125} \mathrm{I}$ - 
VIP and iodinated synthetic fragments with the retention time of ${ }^{125} \mathrm{I}$ radiolabel recovered from lung effluent. Coelution of radiolabel with synthetic standard on two distinct HPLC protocols was required for radiopeptide identification. RP-HPLC separation was accomplished using a programmable multiwavelength detector (model 490) pump (model 510 ) and a $3.9 \times 300 \mathrm{~mm}, \mathrm{C}_{18}$ reverse-phase column (Nova$\mathrm{Pak}^{\circledR}$ ) (all from Waters Instruments, Milford, MA) at a flow rate of 1 $\mathrm{ml} / \mathrm{min}$. The initial mobile phase for both HPLC protocols was HPLC grade $\mathrm{H}_{2} \mathrm{O}$ with $0.1 \%$ TFA. In elution protocol 1 , the column was eluted with a $0.7-49 \%$ linear gradient of acetonitrile over $40 \mathrm{~min}$. In elution protocol 2, the column was eluted with a $14-49 \%$ linear gradient of acetonitrile over $55 \mathrm{~min}$. 30-s fractions were collected and ${ }^{125} \mathrm{I}$ content determined by gamma counting (Packard Instrument Co., Inc., Sterling, VA). Authentic standards for all peptides were processed through the system without a lung present; the recovery among the various peptide was 33-95\%; radiochromatograms were corrected for the background activity and for losses due to processing. The inhibitor combinations used had no effect on the elution time of the VIP breakdown products.

Materials. VIP (guinea pig) 1-28, VIP fragments 1-21, 5-14, 5-21, 5-22, 5-28, 9-10, 10-11, 21-22, 22-23, 22-28, and VIP (guinea pig) antisera were obtained from Peninsula Laboratories Inc.). VIP fragments 1-22, 1-14, and 5-22 were custom synthesized by Hospital Peptide Services (Boston, MA). VIP 4-14 was custom synthesized by Research Genetics (Huntsville, AL). Glutaraldehyde, captopril, bestatin, leupeptin, aprotinin, soybean trypsin inhibitor, chloramine-T, metabisulfite, and methacholine were obtained from Sigma Chemical Co. (St. Louis, MO). SCH 32615 was the kind gift of Schering Corporation (Kenilworth, NJ). All other materials were HPLC or reagent grade as appropriate.

Statistical analysis. All values are expressed as mean $\pm 95 \%$ confidence intervals $(\mathrm{CI})$, unless otherwise stated. The statistical significance of differences between means was determined by analysis of variance. $P$ $<0.05$ was considered significant. When analysis of variance indicated a significant difference the Newman-Keuls test was used to determine which groups were significantly different from each other.

\section{Results}

\section{Pulmonary relaxation}

Dose-response relationship of VIP on pulmonary relaxation. Fig. 1 presents the dose-response relationship for VIP on Pao, measured in the tracheal superfused guinea pig lung. Increasing doses of VIP were associated with a progressive fall in Pao. The $\mathrm{ID}_{50}$ was $0.38 \mathrm{nmol} / \mathrm{kg}(95 \% \mathrm{CI}, 0.33-0.54)$. The superfused lung VIP ID 50 of $0.38 \mathrm{nmol} / \mathrm{kg}$ equates to an approximate $\mathrm{IC}_{50}$ of $12.6 \mathrm{nM}$, assuming an approximate dilution volume of 30 $\mathrm{ml}$, which is similar to the reported tissue bath $\mathrm{IC}_{50}$ for $\operatorname{VIP}(2$, $10,22,23)$. The maximal relaxation after $100 \mathrm{nmol} / \mathrm{kg}$ VIP was $52 \mathrm{~cm} \mathrm{H}_{2} \mathrm{O}$ (95\% CI, 34-71). The maximal relaxation after 10 $\mathrm{nmol} / \mathrm{kg}$ isoproterenol was $56 \mathrm{~cm} \mathrm{H}_{2} \mathrm{O}(95 \% \mathrm{CI}, 37-74)$; compared with the fall in Pao after $100 \mathrm{nmol} / \mathrm{kg}$ VIP this difference was not significant $(P=0.79)$. None of the VIP fragments had pulmonary relaxant activity. Fig. $3 A$ presents the effect of VIP on the maximal fall in Pao. Comparison of results from the group receiving only VIP (VIP) to the group not receiving VIP (NO VIP) demonstrates that VIP injection was associated with a significantly greater maximal decrease in $\mathrm{PaO}, 33 \mathrm{~cm} \mathrm{H}$ (95\% CI, 24-43) in the VIP group and $3 \mathrm{~cm} \mathrm{H}_{2} \mathrm{O}(95 \% \mathrm{CI}$, $-6-13)$ in the NO VIP group. A significantly greater fall in Pao was observed in all groups receiving VIP compared with the NO VIP group $(P<0.001)$.

Time course of VIP-induced changes in Pao. The time course and magnitude of changes in Pao after tracheal injection

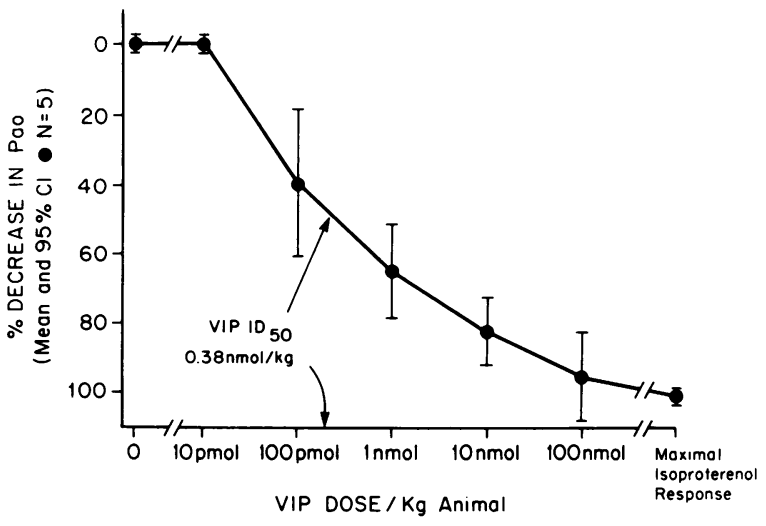

Figure 1. Airway opening pressure as a function of geometrically increasing doses of tracheally injected VIP. The $\mathrm{ID}_{50}$ was $0.38(95 \% \mathrm{CI}$, $0.33-0.54) \mathrm{nmol} / \mathrm{kg}$ VIP. Data are presented as the group mean with $95 \% \mathrm{CI}, n=5$.

of saline or $1 \mathrm{nmol} / \mathrm{kg}$ VIP and the time course of appearance of VIP-like immunoreactivity (VIP-LI) in lung effluent are shown in Fig. 2. Tracheal infusion of VIP was associated with a significant $(P<0.0001)$ decline in Pao. The time for 50\% relaxation was $1.5 \mathrm{~min}(95 \% \mathrm{Cl}, 0.9-2.1)$. Maximal relaxation was achieved by $\sim 4$ min and Pao returned toward baseline over 15 min. Similar time courses were observed in lungs treated with enzyme inhibitors (data not shown).

Effects of active enzyme inhibitors on Pao. We found that the TS and AS combinations significantly enhanced VIP-induced pulmonary relaxation. In the presence of TS, VIP injection resulted in a Pao decrease of $55 \mathrm{~cm} \mathrm{H}_{2} \mathrm{O}(95 \% \mathrm{CI}$, 45-64), whereas the presence of $\mathrm{AS}$ was associated with a Pao decrease of $61 \mathrm{~cm} \mathrm{H}_{2} \mathrm{O}$ (95\% CI, 52-71). The changes in Pao for the AS and TS groups were significantly different from those in the VIP, S, T, A and CBLS groups, $P<0.001$, for each comparison.

Effects of single inhibitors on Pao. There was no significant difference in the Pao response between the VIP group (without inhibitors) and the groups receiving only one of the inhibitors. Pao decreased $27 \mathrm{~cm} \mathrm{H}_{2} \mathrm{O}$ (95\% CI, 18-37) in the A group, 34 $\mathrm{cm} \mathrm{H}_{2} \mathrm{O}(95 \% \mathrm{CI}, 44-25)$ in the $\mathrm{S}$ group, and $25 \mathrm{~cm} \mathrm{H}_{2} \mathrm{O}$ (95\% CI, 15-34) in the T group, all $P=$ NS compared with the no inhibitor (VIP) group.

Effects of combined inhibitors on Pao. In the absence of VIP infusion, the inhibitors did not induce a decrease in Pao (data not shown). When CBL was added to AS or TS, giving CABLS or CTBLS, no further enhancement of VIP-induced pulmonary relaxation was observed. Pao decreased $53 \mathrm{~cm} \mathrm{H}_{2} \mathrm{O}(95 \%$ $\mathrm{CI}, 62-44, P<0.001)$ in the CABLS group and decreased 59 $\mathrm{cm} \mathrm{H}_{2} \mathrm{O}(95 \% \mathrm{CI}, 50-69, P<0.001)$ in the CTBLS group. Although not significantly different from the AS or TS groups, the changes in Pao for the CABLS or CTBLS groups were significantly different than the VIP, S, T, A, and CBLS groups, $P$ $<0.01$ for each comparison. The changes in Pao in the CBLS group, which was treated with a combination of inhibitors that contained all of the inhibitors except aprotinin and soybean trypsin inhibitor, was not significantly different from the VIP only group. In this CBLS group, Pao decreased $33 \mathrm{~cm} \mathrm{H}_{2} \mathrm{O}$ (95\% CI, 23-42) $P=$ NS compared with the VIP and single inhibitor groups. 

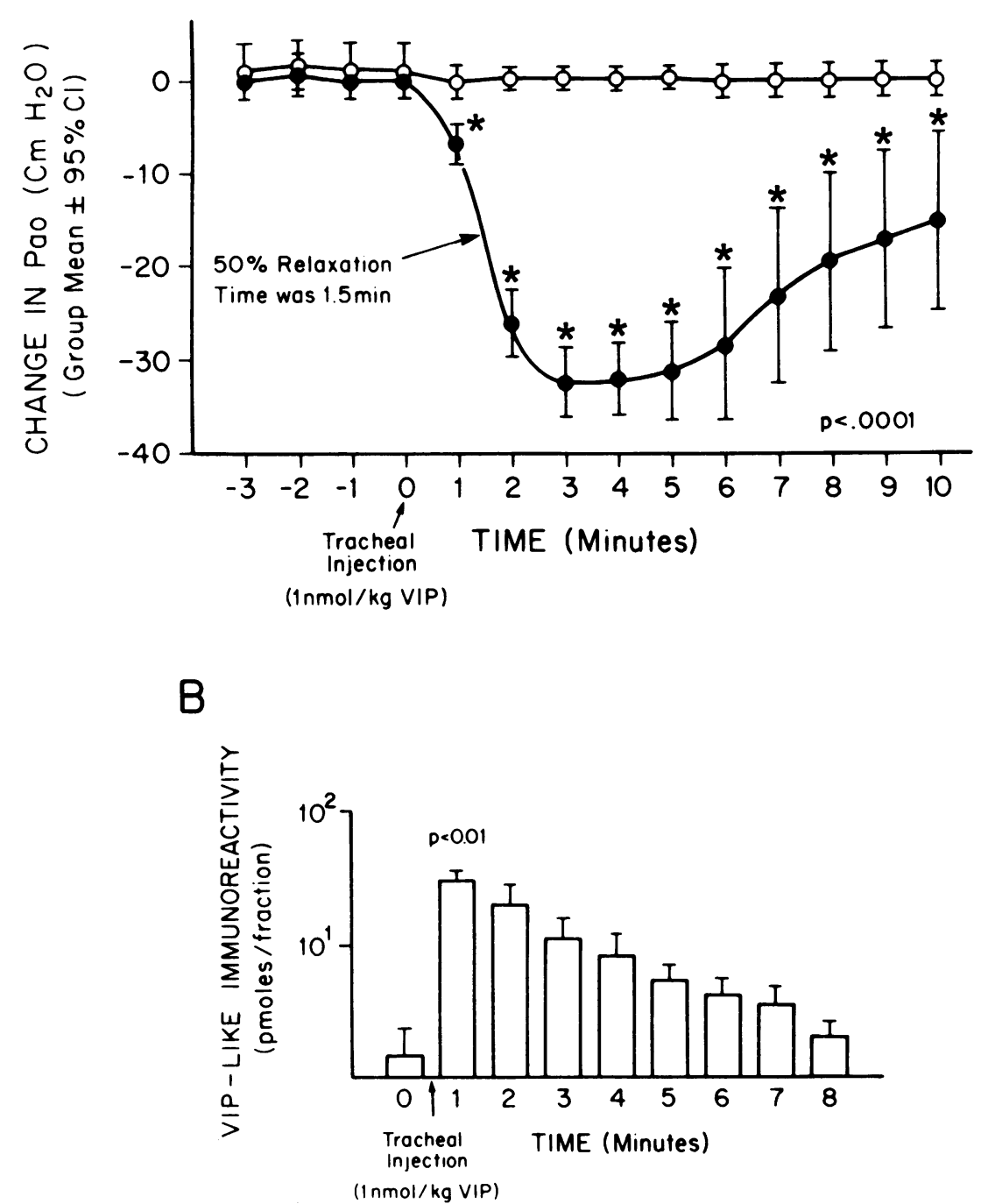

Figure 2. (A) Time course of the decrease in Pao after tracheal injection of $1 \mathrm{nmol} / \mathrm{kg}$ VIP. The mean time for $50 \%$ relaxation was $1.5(95 \% \mathrm{CI}$, 0.9-2.1) min. Data are presented as the group mean with $95 \% \mathrm{CI}, n=5,{ }^{*} P<0.0001$ for lungs receiving VIP (solid circles) compared with buffer-injected control lungs not receiving VIP (open circles). (B) Time course of recovery of VIP-LI from lung effluent after VIP tracheal injection. Data are presented as the mean and SEM, $n=3, T P<0.01$ compared with lung effluent VIP-LI before VIP injection.

\section{Recovery of VIP-like immunoreactivity}

Time course of VIP-induced changes in VIP recovery. The time course and magnitude of changes in the appearance of VIP-LI in lung effluent are shown in Fig. 2. Tracheal infusion of 1 $\mathrm{nmol} / \mathrm{kg}$ VIP was associated with a significant $(P<0.01)$ increase in VIP-LI detected by immunoassay in 1-min fractions of lung effluent. When 5-min fractions of lung effluent were immunoassayed, VIP-LI increased from $1.6(95 \% \mathrm{CI}, 0-5.3)$ to $30 \mathrm{pmol}(9.3-51)$ after tracheal injection of $1 \mathrm{nmol} / \mathrm{kg}$ VIP $(P$ $<0.01) ; 33 \pm 4.6 \%$ (mean \pm SEM) of the injected VIP dose was recovered as VIP-LI. This is similar to the data presented in Fig. 3, which shows a significant increase in VIP-LI in all groups receiving VIP compared with the NO VIP group $(P$ $<0.001)$. The total recovery of radiolabel after tracheal injection of ${ }^{125}$ I-VIP was $94 \pm 3 \%$; this was not significantly different from the recovery of ${ }^{125}$ I when ${ }^{125}$ I-VIP was injected into the perfusion apparatus without a lung present.

Effects of active inhibitors on VIP-LI recovery. We found that the TS and AS combinations significantly increased VIPLI recovery from lung effluent. The changes for the AS and TS groups were significantly different from those in the VIP, S, T, $\mathrm{A}$, and CBLS groups, $P<0.001$ for each comparison.

Effects of single inhibitors on VIP-LI recovery. There was no significant difference in lung effluent VIP-LI between the VIP group (without inhibitors) and the groups receiving only one of the inhibitors. Lung effluent from the A group contained 13 pmol (95\% CI, 5-21), the $S$ group contained $14 \mathrm{pmol}$ (95\% CI, 6-22), the T group contained $13 \mathrm{pmol}(95 \% \mathrm{CI}, 5-21)$, and the no inhibitor VIP group contained $18 \mathrm{pmol}(95 \% \mathrm{CI}$, 10-26), all $P=$ NS.

Effects of combined inhibitors on VIP-LI recovery. When CBL was added to AS or TS, giving CABLS or CTBLS, no further enhancement of peptide recovery was observed. Although not significantly different from the AS or TS groups, the changes in the CABLS and CTBLS groups were significantly different from the VIP, S, T, A, and CBLS groups, $P$ $<0.01$ for each comparison. The changes in Pao in the CBLS group, which was treated with a combination of inhibitors that contained all of the inhibitors except aprotinin and soybean trypsin inhibitor, was not significantly different from the VIP only group. In this CBLS group 26 pmol VIP-LI (95\% CI, 18- 
A

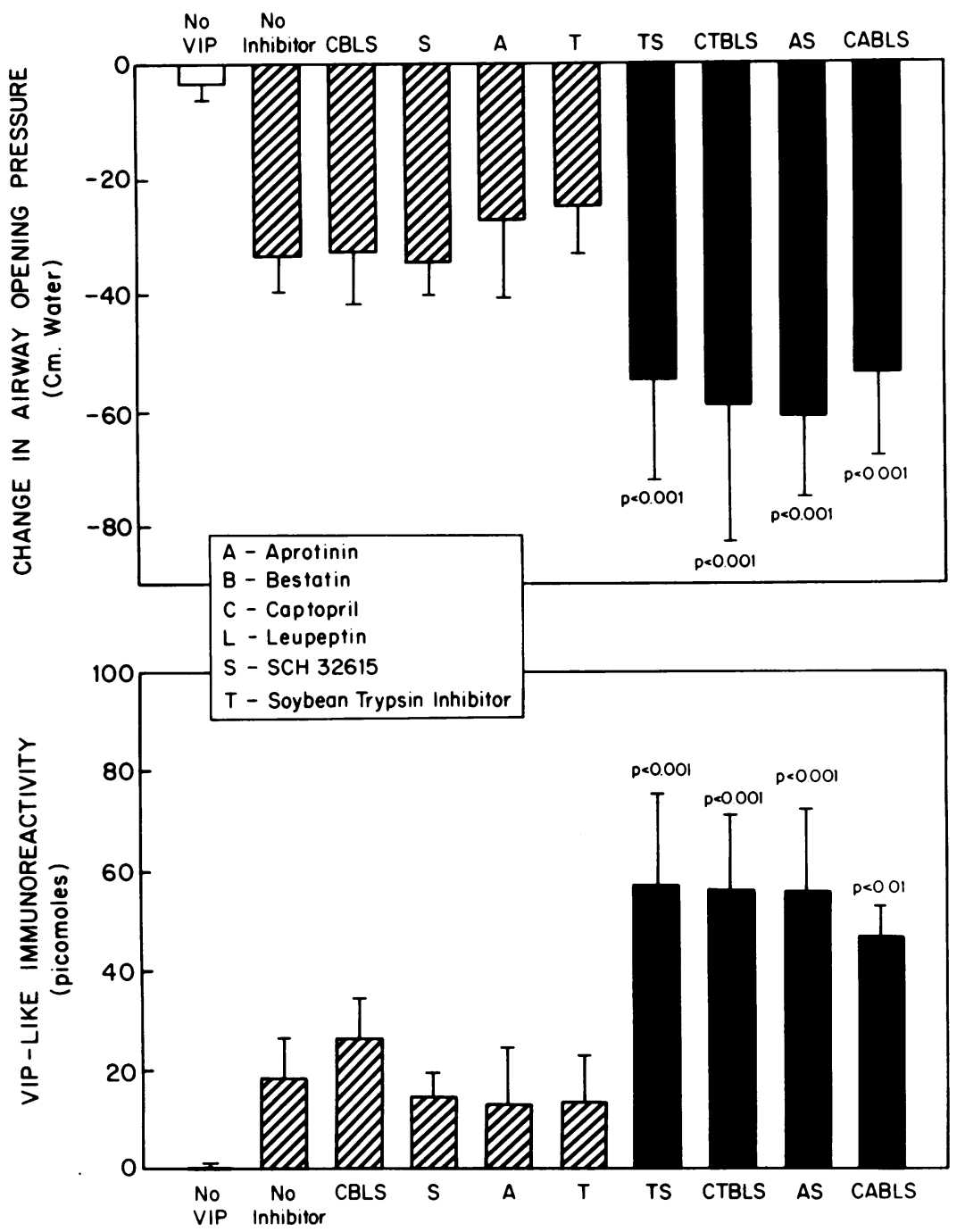

Figure 3. $(A)$ Pao response after tracheal injection of $1 \mathrm{nmol} / \mathrm{kg}$ VIP. Data shown are means with 95\% CI for groups of five lungs treated with single inhibitors designated by single letters, with combinations of inhibitors designated by combinations of letters, or control lungs.
34) was recovered from lung effluent, both $P=$ NS compared with the VIP and single inhibitor groups.

Identification of ${ }^{125} I-V I P$ hydrolysis fragments. Our data on the magnitude of physiological response and recovery of VIPLI were consistent with enzymatic degradation as limiting the pulmonary relaxant activity of VIP. Furthermore, the requirement for two enzyme inhibitors suggested that NEP, as inhibited by its specific inhibitor SCH 32615, and enzymes inhibited both by aprotinin and soybean trypsin inhibitor were the enzyme systems limiting VIP activity. To confirm that VIP pulmonary relaxant activity is limited by enzymatic degradation and to identify the physiologically relevant enzyme systems, we identified the major breakdown products of ${ }^{125} \mathrm{I}-\mathrm{VIP}$ in superfused lung effluent. Further, we examined the effects of the physiologically active enzyme inhibitors on the qualitative recovery of these ${ }^{125}$ I-VIP breakdown products. Resolution of the recovered radiolabel by RP-HPLC allowed separation of VIP from its enzymatic cleavage products and fragment identification was accomplished by co-chromatography with synthetic standards (Fig. 4). When both physiologically active enzyme inhibitors were present, the percentage of total counts recovered that coeluted with intact VIP increased from 29 to $68 \%$. The magnitude of this increase is similar to the increase in
VIP-LI observed with these same inhibitors present (Fig. 3). Once we confirmed that the physiologically active inhibitors increased the recovery of intact VIP from lung effluent and decreased the fraction of the radiolabel coeluting with VIP cleavage products, we identified and quantified the specific cleavage products present in lung effluent. We were able to implicate specific enzyme systems by comparing the observed VIP breakdown products with VIP cleavage products deduced from known VIP cleavage sites (Fig. 5). When neither S nor A was present, $29 \%$ of the radiolabel coeluted with intact VIP. $40 \%$ of the radiolabel coeluted with VIP $4 / 5-14$ (VIP 4-14 or VIP 5-14), $16 \%$ of the radiolabel coeluted with VIP 1-14, and $7 \%$ of the counts coeluted with VIP 5-21/22 (VIP 5-21 or VIP $5-22$ ) (Fig. 6). We were able to account for $92 \%$ of the administered radiolabel. When $\mathrm{S}$ was present and $\mathrm{A}$ was not present, $26 \%$ of the radiolabel coeluted with intact VIP. The percentage of the radiolabel coeluting with VIP 4/5-14, products of NEP and tryptic cleavage, decreased to $24 \%$. The percentage of the radiolabel coeluting with the tryptic product VIP 1-14 increased to $43 \%$. We were able to account for $93 \%$ of the administered radiolabel. When $\mathrm{A}$ was present and $\mathrm{S}$ was not present, $24 \%$ of the radiolabel coeluted with intact VIP. $70 \%$ of the radiolabel coeluted with VIP 5-21/22. We were able to account 
A

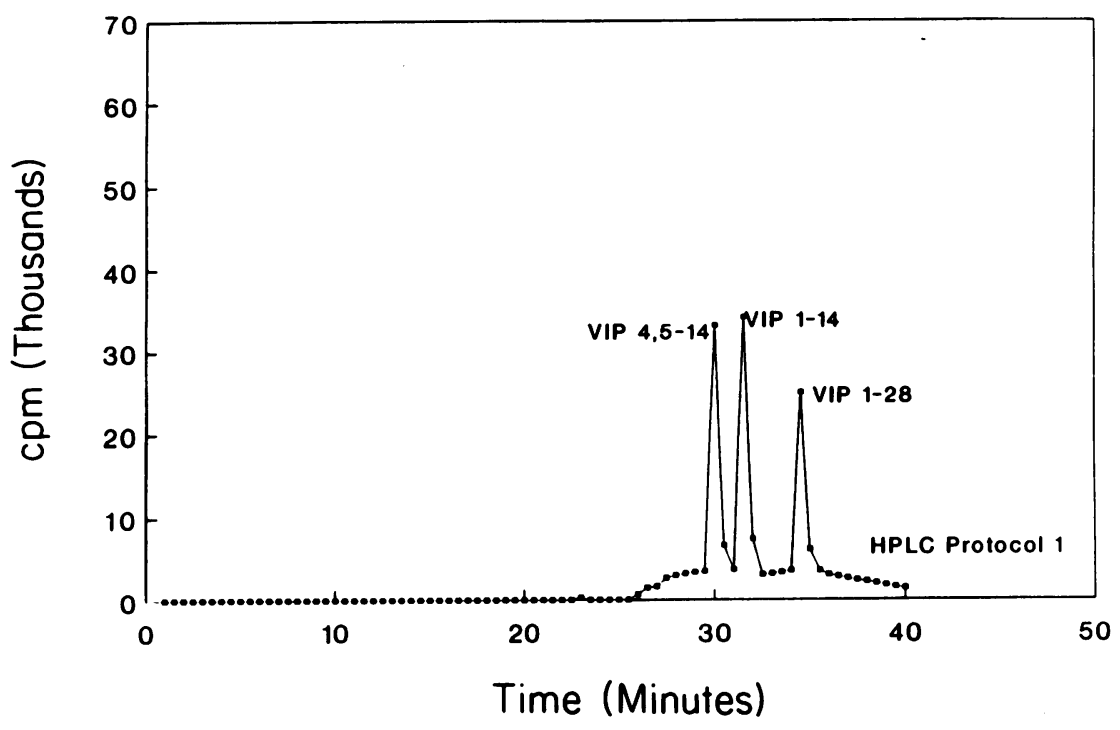

B

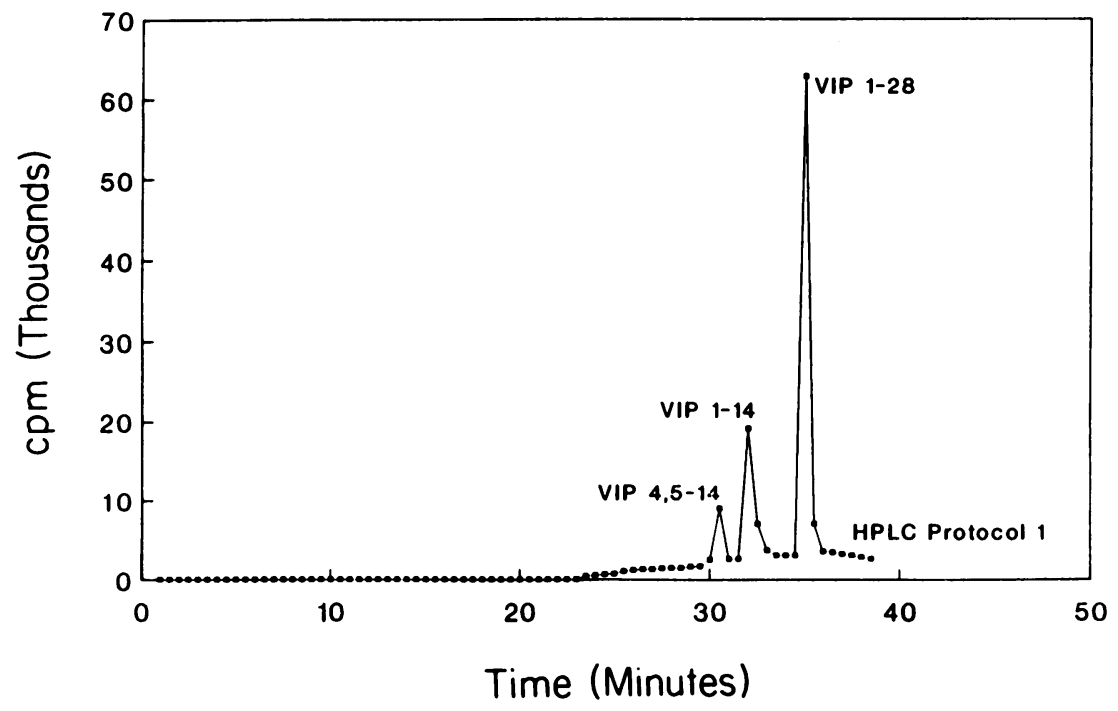

Figure 4. RP-HPLC resolution of intact ${ }^{125} \mathrm{I}-\mathrm{VIP}$ $1-28$ from ${ }^{125} \mathrm{I}-\mathrm{VIP}$ cleavage products in lung effluent, identified as ${ }^{125} \mathrm{I}$-VIP $4 / 5-14$ and ${ }^{125} \mathrm{I}$ VIP 1-14. $(A)$ In the absence of and $(B)$ in the presence of SCH 32615 and aprotinin.

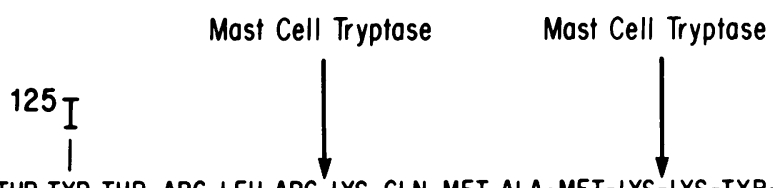

HIS-SER-ASP-ALA-LEU-PHE-THR-ASP-THR-TYR-THR-ARG-LEU-ARG-LYS-GLN-MET-ALA-MET-LYS-LYS-TYR-LEU-ASN-SER-VAL-LEU-ASN-NH 2

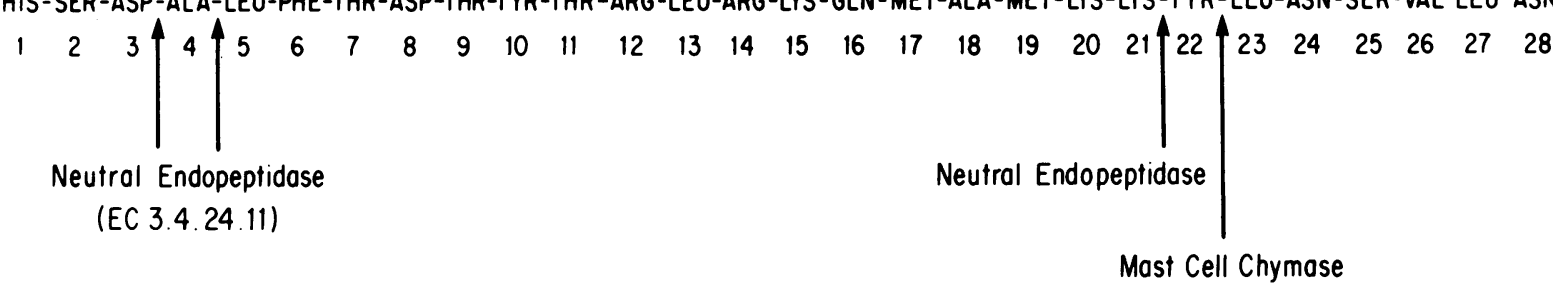

Figure 5. The most active cleavage sites for VIP (guinea pig) for the limited number of enzymes known to cleave VIP under physiological conditions are shown. 


\section{CONDITION 1}
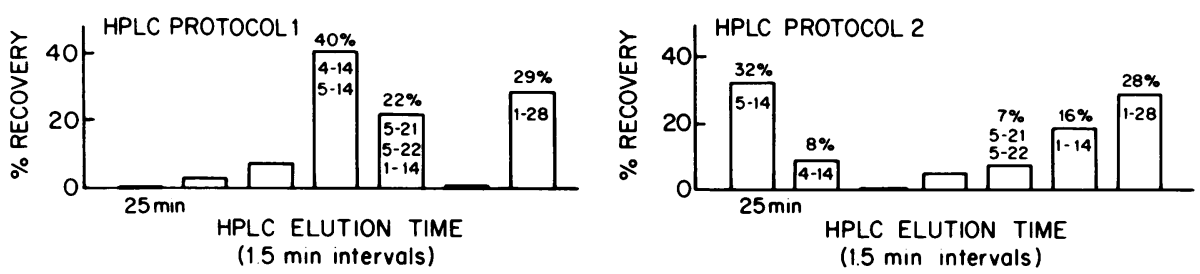

CONDITION 2
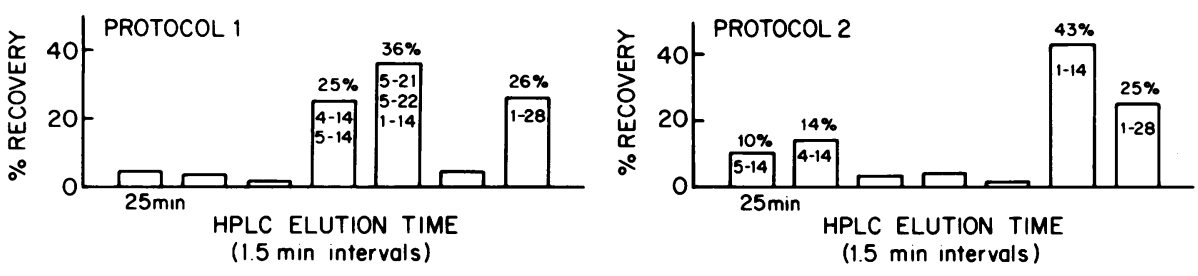

CONDITION 3
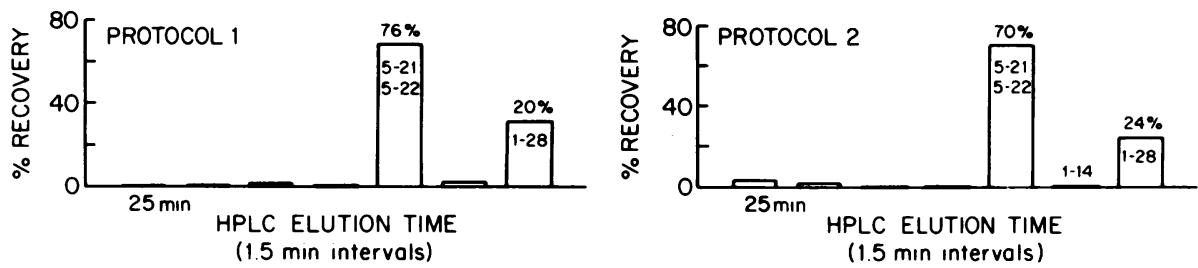

Figure 6. ${ }^{125} \mathrm{I}-\mathrm{VIP}$ and ${ }^{125} \mathrm{I}-$ VIP breakdown products identified by cochromatography with synthetic standards on two HPLC protocols. In condition 1 , with neither $\mathrm{S}$ nor A present, $28 \%$ of the radiolabel coeluted with ${ }^{125}$ I-VIP, $40 \%$ coeluted with ${ }^{125}$ I-VIP 4/514 (a product of NEP and tryptase cleavage), and $16 \%$ coeluted with ${ }^{125}$ I-VIP 1-14 (a tryptase product). In condition 2, with $S$ present and A not present, $25 \%$ of the radiolabel coeluted with ${ }^{125}$ I-VIP, while the activity coeluting with ${ }^{125}$ I-VIP 1-14 (the tryptase product) increased to $43 \%$ and activity coeluting with ${ }^{125}$ I-VIP 4/514 decreased to $24 \%$. In condition 3, with S not present and A present, $24 \%$ of the radiolabel coeluted with ${ }^{125}$ I-VIP and $70 \%$ of the radiolabel coeluted with ${ }^{125}$ I-VIP 5-21/22, a product of NEP cleavage. for $94 \%$ of the administered radiolabel. VIP 1-22 (a potential chymase product) was not identified under any of the conditions studied.

\section{Discussion}

Our data demonstrate that combinations of the specific NEP inhibitor SCH 32615 (24) and a serine protease inhibitor, aprotinin or soybean trypsin inhibitor, significantly increase VIPinduced pulmonary relaxation and the recovery of intact VIP. The same enzyme inhibitor combinations enhance recovery of intact VIP from lung effluent. Taken together these findings support the hypothesis that the pulmonary relaxant activity of VIP is limited by enzymatic degradation by more than one enzyme system. The relevant enzyme systems are likely to be NEP and another enzyme system whose actions are limited both by aprotinin and soybean trypsin inhibitor.

Aprotinin and soybean trypsin inhibitor are broad spectrum inhibitors $(2,3)$, each can inhibit serine proteases, including a number of tryptic enzymes potentially found in the lung. Tryptase and chymase are the only enzymes for which VIP cleavage sites have been reported (Fig. 5) that may also be sensitive to both aprotinin and soybean trypsin inhibitor $(25,26)$. We isolated radiolabeled VIP cleavage fragments from lung effluent and identified them as VIP 5-21/22 and VIP 1-14; these are expected VIP cleavage products for NEP and a tryptic enzyme. The observed changes in the VIP fragment profile, in the presence and absence of enzyme inhibitors, can be fully explained by inhibition of NEP and a tryptic moiety; we did not identify any VIP cleavage products that could only be explained by chymase activity. When both SCH 32615 and aprotinin were present in the perfusate (Fig. 4), the recovery of intact VIP (1-28) increased and the recovery of VIP cleavage products (VIP 4/5-14 and 1-14) decreased compared with VIP recovery in the absence of these enzyme inhibitors. Furthermore, the magnitude of increase of intact ${ }^{125} \mathrm{I}$-VIP recovery was similar to the increase in VIP-LI when inhibitor combination AS was present, confirming the results of the ELISA study. When neither aprotinin nor SCH 32615 was present (condition 1, Fig. 6), products consistent with tryptic activity (VIP 1-14) and combined NEP and tryptic activity (VIP 4/5-14) were identified in lung effluent. When NEP was inhibited by SCH 32615 but aprotinin was absent, (condition 2, Fig. 6), there was decreased recovery of products consistent with NEP activity (VIP 4/5-14) and increased recovery of VIP 1-14, a product consistent with tryptic activity. When SCH 32615 was absent from and aprotinin was present in the perfusion buffer (condition 3, Fig. 6), the recovery of products consistent with NEP activity increased and the product consistent with tryptic activity was absent. In each condition, the changes in VIP product recovery profile are those that would be expected from inhibition of NEP (SCH 32615) and a tryptic enzyme (aprotinin) whose identity remains unknown but whose cleavage site is at the VIP 14-15 bond. In each case the radiolabeled fragments accounted for $>90 \%$ of the radiolabeled peptide offered to the lung. In addition to implicating NEP and a tryptic enzyme, these data diminish the potential physiological importance of angiotensin-converting enzyme, aminopeptidases, and car- 
boxypeptidases in limiting VIP activity. The failure of $\mathrm{L}$ to enhance VIP recovery or decrease in Pao suggests that it is not an effective inhibitor of guinea pig tryptic enzymes. Since the cleavage products were shown to be physiologically inactive and the presence of intact ${ }^{125}$ I-VIP or VIP-LI in lung effluent correlates with VIP-induced pulmonary relaxation, these findings strongly support the hypothesis that the magnitude of VIPinduced pulmonary relaxation is limited by enzymatic degradation.

Our data are consistent with NEP and a tryptic enzyme as the physiologically relevant systems responsible for VIP inactivation. NEP is known to have an important regulatory role in the pulmonary microenvironment. In the lung, NEP has been localized to epithelial cells and airway smooth muscle cells (27-29). It is well established that the bronchoconstrictor neuropeptides substance-P and neurokinin-A have their physiological activity limited by enzymatic degradation at or near their site of release or action. Neurokinin-A pulmonary activity is limited by NEP $(19,30)$, whereas SP is limited by both NEP and angiotensin-converting enzyme. VIP is a known substrate for NEP (Fig. 5) $(13,31)$. However, despite the availability of specific inhibitors it has been difficult to demonstrate a role for NEP in regulating VIP physiological activity. When VIP-induced relaxation in guinea pig (2) and human (3) tracheal rings was studied in the presence of enzyme inhibitors, inhibitor combinations that combined a NEP inhibitor with aprotinin or soybean trypsin inhibitor augmented the relaxant effects of VIP; single inhibitors had little physiological effect. Therefore, even though NEP activity has the capacity to limit VIP-induced pulmonary relaxation, other enzyme systems are physiologically competitive with NEP.

Among tryptic enzymes known to be resident in lung tissues, tryptase is stored in and released from mast cells (32) and has been implicated (33), but not widely recognized, as a modulator of peptide activity. Since a proportion of mast cells is located at the site of peptidergic nerve terminals (34-36), such cells are uniquely poised to exert a regulatory role in this microenvironment. VIP is known to be a substrate for tryptase (14) and the addition of tryptase has been shown to reverse VIP-induced tracheal relaxation in vitro (37). We identified, in lung effluent, VIP cleavage products that would be expected to result from tryptase activity and combined tryptase and NEP activity. Taken together these findings are consistent with tryptase as the tryptic enzyme that modulates VIP-induced pulmonary relaxation. This is a striking finding since by enzyme histochemistry guinea pig mast cells contain virtually no tryptic activity $(33,38)$. It is possible however that tryptase is not stored in guinea pig mast cells in the concentrated form detected by this method. It is also well established that mast cell tryptase activity likely represents action of a family of mast cell proteases with related but distinct amino acid sequences, substrate specificity, inhibitor sensitivity, and immunoreactivity $(39,40)$. Our data support the presence of a physiologically active enzyme consistent with mast cell tryptase in the guinea pig lung.

In summary, we have demonstrated that VIP-induced pulmonary relaxation is limited by enzymatic degradation by two equally important enzyme systems that are physiologically competitive with the VIP receptor for terminating the effects of VIP. Our data support the identification of these two enzyme systems as NEP and a tryptic enzyme. These findings demon- strate that a regulatory scheme, involving the simultaneous action of multiple enzymes limiting VIP pulmonary relaxation, which has been proposed by others $(2,3)$, is of physiological significance.

\section{Acknowledgments}

The authors thank Dr. Bernard Ransil for his helpful advice concerning statistical analysis. Data analysis was performed on the Core Lab computer facilities of the Beth Israel Hospital.

This work was supported by National Institutes of Health grant HL-39827 and a grant from the Brazilian National Council for Scientific Development (CNPQ).

\section{References}

1. Said, S. I., and V. Mutt. 1969. Long acting vasodilator peptide from lung tissue. Nature (Lond.). 224:699-700.

2. Thompson, D. C., L. Diamond, and R. J. Altiere. 1990. Enzymatic modulation of vasoactive intestinal peptide and nonadrenergic noncholinergic inhibitory responses in guinea pig tracheae. Am. Rev. Respir. Dis. 142:1119-1123.

3. Tam, E. K., G. M. Franconi, J. A. Nadel, and G. H. Caughey. 1990. Protease inhibitors potentiate smooth muscle relaxation induced by vasoactive intestinal peptide in isolated human bronchi. Am. J. Respir. Cell. Mol. Biol. 2:449-452.

4. Dey, R. D., W. A. Shannon, and S. I. Said. 1981. Localization of VIP-immunoreactive nerves in airways and pulmonary vessels of dogs, cats, and human subjects. Cell Tissue Res. 220:231-238.

5. Dey, R. D., J. B. Altemus, and M. Michalkiewicz. 1991. Distribution of vasoactive intestinal peptide- and substance-P-containing nerves originating from neurons of airway ganglia in cat bronchi. J. Comp. Neurol. 304:330-340.

6. Laitinen, A., M. Partanen, A. Hervonen, M. Pelto-Huikko, and L. A. Laitinen. 1985. VIP like immunoreactive nerves in human respiratory tract; light and electron microscopic study. Histochemistry. 82:313-319.

7. Saga, T., and S. I. Said. 1984. Vasoactive intestinal peptide relaxes isolated strips of human bronchus, pulmonary artery and lung parenchyma. Trans. Assoc. Am. Physicians. 97:304-310.

8. Palmer, J. B. D., F. M. C. Cuss, and P. J. Barnes. 1987. VIP and PHM and their role in nonadrenergic inhibitory responses in isolated human airways. $J$. Appl. Physiol. 61:1322-1328.

9. Coles, S. J., S. I. Said, and L. M. Reid. 1981. Inhibition by VIP of glyconconjugate and lysozyme secretion by human airways in vitro. Am. Rev. Respir. Dis. 124:531-536.

10. Webber, S. E., and J. G. Widdicombe. 1987. The effect of vasoactive intestinal peptide on smooth muscle tone and mucus secretion from the ferret trachea. Br. J. Pharmacol. 91:139-148.

11. Farmer, S. G., and J. Togo. 1990. Effects of epithelium removal on relaxation of airway smooth muscle induced by vasoactive intestinal peptide and electrical field stimulation. Br. J. Pharmacol. 100:73-78.

12. Hachisu, M., T. Hiranuma, S. Tani, and T. Izuka. 1991. Enzymatic degradation of helodermin and vasoactive intestinal polypeptide. J. Pharmacobio-dyn. 14:126-131.

13. Goetzl, E. J., S. P. Sreedharan, C. W. Turck, R. Bridenbaugh, and B. Malfroy. 1989. Preferential cleavage of amino- and carboxyl-terminal oligopeptides from vasoactive intestinal polypeptide by human recombinant enkephalinase (neutral endopeptidase, EC 3.4.24.11). Biochem. Biophys. Res. Commun. 158:850-854.

14. Caughey, G. H., F. Leidig, N. F. Viro, and J. A. Nadel. 1988. Substance P and vasoactive intestinal peptide degradation by mast cell tryptase and chymase. J. Pharmacol. Exp. Ther. 244:133-137.

15. Powers, J. C., T. Tanaka, J. W. Harper, Y. Minematsu, L. Barker, D. Lincoln, K. V. Crumley, J. E. Fraki, N. M. Schechter, G. G. Lazarus, et al. 1985. Mammalian chymotrypsin-like enzymes. Comparative reactivities of rat mast cell proteases, human and $\operatorname{dog}$ skin chymases, and human cathepsin $G$ with peptide 4-nitroanilide substrates and with peptide chloromethyl ketone and sulfonyl flouride inhibitors. Biochemistry. 24:2048-2058.

16. Tanaka, T., B. J. McRae, K. Cho, R. Cook, J. E. Fraki, D. A. Johnson, and J. C. Powers. 1983. Mammalian trypsin-like enzymes. Comparative analysis of human skin tryptase, human lung tryptase, and bovine trypsin with peptide 4-nitroanilide and thioester substrates. J. Biol. Chem. 258:13552-13557.

17. Bodansky, M., Y. S. Klausner, and S. I. Said. 1983. Biologic activities of synthetic peptides corresponding to fragments of and to the entire sequence of vasoactive intestinal peptide. Proc. Natl. Acad. Sci. USA. 70:382-384.

18. De Nucci, G., and S. Moncada. 1987. Release of vasoactive substances 
from guinea pig isolated lungs perfused via the trachea. Am. Rev. Respir. Dis. 135:S39-S41.

19. Martins, M. A., S. A. Shore, N. P. Gerard, C. Gerard, and J. M. Drazen. 1990. Peptidase modulation of the pulmonary effects of tachykinins in tracheal superfused guinea pig lungs. J. Clin. Invest. 85:170-176.

20. Folkesson, R., A. Neil, and L. Terenius. 1985. Enzyme-linked immunosorbent assay of substance-P and its metabolite SP 1-7. A comparison with RIA. J. Neurosci. Methods. 14:169-176.

21. Martin, J. L., K. Rose, G. J. Hughes, and P. J. Magistretti. 1986. (mono ${ }^{125}$ iodo- Tyr $^{10}, \mathrm{MetO}^{17}$ )-Vasoactive intestinal polypeptide. J. Biol. Chem. 261:5320-5327.

22. Stretton, D. C., M. G. Belvisi, and P. J. Barnes. 1990. Sensory depletion potentiates inhibitory non-adrenergic, non-cholinergic nerves in guinea pig airways. Eur J. Pharmacol. 184:333-337.

23. Shikada, K., A. Yamamoto, and S. Tanaka. 1991. Effects of phosphodiesterase inhibitors on vasoactive intestinal peptide-induced relaxation of isolated guinea pig trachea. Eur J. Pharmacol. 195:389-394.

24. Yaksh, T. L., M. B. Sabbe, D. Lucas, E. Mjanger, and R. E. Chipkin. 1991. Effects of ( $N$-(L-(1-carboxyl-2-phenyl)ethyl))-L-phenylalanyl-beta-alanine (SCH 32615) a neutral endopeptidase (enkephalinase) inhibitor, on levels of enkephalin, encrypted enkephalins and substance $P$ in cerebral spinal fluid and plasma of primates. J. Pharmacol. Exp. Ther. 256:1033-1041.

25. Caughey, G. A., N. F. Viro, J. Ramachandran, S. C. Lazarus, D. B. Borson, and J. A. Nadel. 1987. Dog mastocytoma tryptase: affinity purification, characterization, and amino-terminal sequence. Arch. Biochem. Biophys. 258:555-563.

26. Caughey, G. A., N. F. Viro, S. C. Lazarus, and J. A. Nadel. 1988. Purification and characterization of dog mastocytoma chymase: identification of an octapeptide conserved in chymotryptic leukocyte proteinases. Biochim. Biophys. Acta. 952:142-149.

27. Matsas, R., A. J. Kenny, and A. J. Turner. 1984. The metabolism of neuropeptides. The hydrolysis of peptides, including enkephalins, tachykinins and their analogues, by endopeptidase-24.11. Biochem. J. 223:433-440.

28. Edros, E. G., and R. A. Skidgel. 1989. Neutral endopeptidase 24.11 (enkephalinase) and related regulators of peptide hormones. FASEB (Fed. Am. Soc. Exp. Biol.) J. 3:145-151.
29. Ryan, J. W. 1989. Peptidase enzymes of the pulmonary vascular surface. Am. J. Physiol. 257:L53-L60.

30. Dusser, D. J., E. Umeno, P. D. Graf, T. Djokic, D. B. Borson, and J. A. Nadel. 1988. Airway neutral endopeptidase-like enzyme modulates tachykinininduced bronchoconstriction in vivo. J. Appl. Physiol. 65:2585-2591.

31. Barbato, G. F., F. Jordan, and B. R. Komisaruk. 1988. The in vitro proteolytic processing of vasoactive intestinal polypeptide by rat spinal cord homogenate. Ann. NY Acad. Sci. 527:582-585.

32. Schwartz, L. B., R. A. Lewis, D. Seldin, and K. F. Austen. 1981. Acid hydrolases and tryptase from secretory granules of dispersed human mast cells. $J$. Immunol. 126:1290-1294.

33. Caughey, G. H. 1989. Role of mast cell tryptase in airway function. Am. J. Physiol. 257:L39-L46.

34. Newson, B., A. Dahlstrom, L. Enerback, and H. Ahlman. 1988. Suggestive evidence for a direct innervation of mucosal mast cells. An electron microscopic study. Neuroscience. 10:565-570.

35. Stead, R. H., M. Tomioka, G. Quinonez, G. T. Simon, S. Y. Felten, and J. Bienenstock. 1987. Intestinal mucosal mast cells in normal and nematode infected rat intestines are in intimate contact with peptidergic nerves. Proc. Natl. Acad. Sci. USA. 84:2975-2979.

36. Weiner-Menzel, L., B. Schultz, F. Vakilzadeh, and B. M. Czarnetzki. 1981. Electron microscopical evidence for a direct contact between nerve fibers and mast cells. Acta Dermato-venereol. 61:465-469.

37. Franconi, G. M., P. D. Graf, S. C. Lazarus, J. A. Nadel, and G. C. Caughey. 1989. Mast cell tryptase and chymase reverse airway smooth muscle relaxation induced by vasoactive intestinal peptide in the ferret. $J$. Pharmacol. Exp. Ther. 248:947-951.

38. Chiu, H., and D. Lagunoff. 1972. Histochemical comparison of vertebrate mast cells. Histochem. J. 4:135-144.

39. Reynolds, D. S., D. S. Gurley, K. F. Austen, and W. E. Serafin. 1991 Cloning of the cDNA and gene of mouse mast cell protease-6. J. Biol. Chem. 266:3847-3853.

40. Serafin, W. E., D. S. Reynolds, S. Rogel, W. S. Lane, G. A. Conder, S. S Johnson, K. F. Austen, and R. L. Stevens. 1990. Identification and molecular cloning of a novel mouse mucosal mast cell serine protease. J. Biol. Chem. 265(1):423-429. 